\title{
Study of the prevalence of lung metastasis of rectal cancer in patients treated with laparoscopic surgery for low rectal cancer at Thanh Nhan Hospital
}

\section{Étude de la prévalence de la métastase pulmonaire du cancer rectal chez les patients traités par le chirurgie laparoscopique pour cancer du bas rectal à l'hôpital Thanh Nhan}

\section{Dao Quang, T. Nguyen Van}

Thanh Nhan Hospital. Hanoi - Vietnam

\begin{abstract}
Introduction. To evaluate the results of laparoscopic surgery for low rectal cancer and the prevalence of lung metastasis at Thanh Nhan hospital from January 2016 to June 2018.

Research method. Descriptive retrospective study.

Results and Discussion. 31 cases of rectal cancer were treated with laparoscopy. Rate of male / female $=17 / 14$, Average age was $63.7 \pm 6.2$, the most common cases was in the group over 60 years old. The clinical symptoms were various, not specific. The indicators of CEA only increased in $41.9 \%$ of cases. The major was lumpy tumors and ulcers with $93.5 \%, \mathrm{CT}$ and MRI evaluated the incidence of sphincter invasion with $42 \%$ and distant metastasis with $56.4 \%$. Lymph nodes over 10 $\mathrm{mm}$ have a risk of metastasis over $76.2 \%$. 21 cases of ISR, 3 cases of Miles, 2 cases of artificial anus. Lung metastasis was $3.2 \%$

Conclusion. Prevalence of lung metastasis of rectal cancer is low. Laparoscopic for low rectal cancer is feasible and beneficial.
\end{abstract}

\section{KEYWORDS: Laparoscopy; Rectum; Lymph node; Metastasis; Lung.}

\section{RÉSUMÉ}

Introduction. Évaluer les résultats de la chirurgie laparoscopique pour cancer du bas rectal et le prévalence de métastase pulmonaire à l'hôpital Thanh Nhan de Janvier 2016 à Juin 2018.

Méthode de recherche. Etude rétrospective descriptive

Résultats. 31 cas de cancer du rectum ont été traités par laparoscopie. Taux d'hommes / femmes = 17/14, l'âge moyen était de 63,7 $\pm 6,2$, les cas les plus fréquents étaient ceux du groupe des plus de 60 ans. Les symptômes cliniques étaient variés et non spécifiques. Les indicateurs de CEA n'ont augmenté que dans 41,9\% des cas. Les principales étaient les tumeurs et les ulcères bosselés avec 93,5\%, la tomodensitométrie et l'IRM évaluaient l'incidence de l'invasion du sphincter avec $42 \%$ et les métastases à distance avec $56,4 \%$. Les ganglions lymphatiques de plus de $10 \mathrm{~mm}$ présentent un risque de métastase supérieur à $76,2 \%$. 21 cas de RSI, 3 cas de milles, 2 cas d'anus artificiel.

Conclusion. La prévalence de métastase pulmonaire du cancer rectal est base. La laparoscopie pour le cancer du rectum bas est réalisable et bénéfique.

MOTS CLÉS: Laparoscopie; Rectum; Ganglion lymphatique; Métastase; Poumon. 


\section{INTRODUCTION}

Low rectal cancer is a malignant disease that accounts for about $40-45 \%$ of rectum cancer. The recommended treatment includes multidisciplinary treatment combined surgery and support therapy, combined or not combined preoperative chemoradiotherapy. The indications for treatment of low rectal cancer depend on the degree of sphincter invasion, tumor stage and some other factors. The methods include cutting low front rectum, cutting the rectum, connecting the anal to keep sphincter, cutting rectum and internal sphincter and cutting bundle of external sphincter, Miles surgery. Etc. Endoscopic surgery treatment of low rectal cancer has been performed in many parts of the world as well as in Vietnam. Endoscopic surgery has demonstrated many advantages both in cancer treatment and less invasion, which helps to recover quickly after surgery. Thanh Nhan Hospital in Hanoi has developed endoscopic surgery to treat low rectal cancer for many cases, achieved encouraging results. We carried out this study with the aim of to evaluate the results of endoscopic surgery to treat low rectal cancer and lung metastasis at Thanh Nhan Hospital in Hanoi.

\section{METHODS}

Subjects: including all cases of low rectal cancer diagnosis with endoscopic surgery at Thanh Nhan hospital - Hanoi, from January of 2016 to June of 2018. Study method: cross-sectional, non-controlled vertical description.

Research indicators: general characteristics, clinical symptoms, laboratory tests, diagnosis images, surgical methods, surgery time, complications in surgery, postoperative complications, number of lymph nodes removed, lymph node metastasis rate, recurrence rate ... Results of postoperative follow-up: cases with support treatment after surgery, 3-month follow-up, evaluation of indicators according to the research samples.

\section{RESULTS}

Age and Gender

\begin{tabular}{lcccc} 
TABLE 1 & \multicolumn{3}{c}{ Age and Gender } \\
\cline { 2 - 5 } Age & \multicolumn{2}{c}{ Male } & \multicolumn{2}{c}{ Female } \\
\cline { 2 - 6 } & $\mathbf{n}$ & $\%$ & $\mathbf{n}$ & $\%$ \\
\hline$<40$ years old & 01 & 3.2 & 01 & 3.2 \\
40-60 years old & 05 & 16 & 04 & 12.9 \\
$>$ 60 years old & 11 & 35.5 & 09 & 29.1 \\
Total & 17 & 54.8 & 14 & 45.2 \\
Average age & \multicolumn{4}{c}{ \pm 13.6} \\
\hline
\end{tabular}

\section{Clinical symptoms}

\begin{tabular}{lcc} 
TABLE 2 & Clinical symptoms & \\
Symptoms & $\mathbf{n}$ & $\mathbf{\%}$ \\
\hline Stomachache & 18 & 58.1 \\
Weight loss & 09 & 29.1 \\
Constipation & 13 & 41.9 \\
Blood in stool & 25 & 80.6 \\
Bowel movements many times & 21 & 67.7 \\
Change in the stool mold & 26 & 83.8 \\
Change of bowel movements habits & 22 & 70.9 \\
\hline
\end{tabular}

\section{CEA tests}

\section{TABLE 3 CEA indicators}

\begin{tabular}{lcc} 
CEA $(\mathbf{n g} / \mathrm{mL})$ & $\mathbf{n}$ & $\%$ \\
\hline$<5 \mathrm{ng} / \mathrm{ml}$ & 18 & 58.1 \\
$>5 \mathrm{ng} / \mathrm{ml}$ & 13 & 41.9 \\
Total & 31 & 100 \\
\hline
\end{tabular}

\section{Rectum endoscopy}

\section{TABLE 4 The results of rectum endoscopy}

\begin{tabular}{llc} 
Tumor forms & $\mathbf{n}$ & $\mathbf{\%}$ \\
\hline Scarly tumors & 09 & 29.1 \\
Ulcer tumor & 06 & 19.4 \\
Scarly and ulcer tumors & 14 & 45.2 \\
Injection tumors & 01 & 3.2 \\
Polyp cancer & 01 & 3.2 \\
\hline
\end{tabular}

The results of CT Scanner and MRI

\section{TABLE 5 The results of CT and MRI}

\begin{tabular}{lcc} 
Damage & $\mathbf{n}$ & $\%$ \\
\hline Invasion over rectal wall & 08 & 25.8 \\
Invasion nearby organization & 03 & 9.7 \\
Invasion internal sphincter & 10 & 32.3 \\
Invasion internal and external & 03 & 9.7 \\
sphincter & 16 & 51.6 \\
Lymph node around the rectum & 08 & 25.8 \\
Lymph node across the arteries & 02 & 6.4 \\
Metastatic organs (liver, lungs) & &
\end{tabular}




\section{Location and invasion rate}

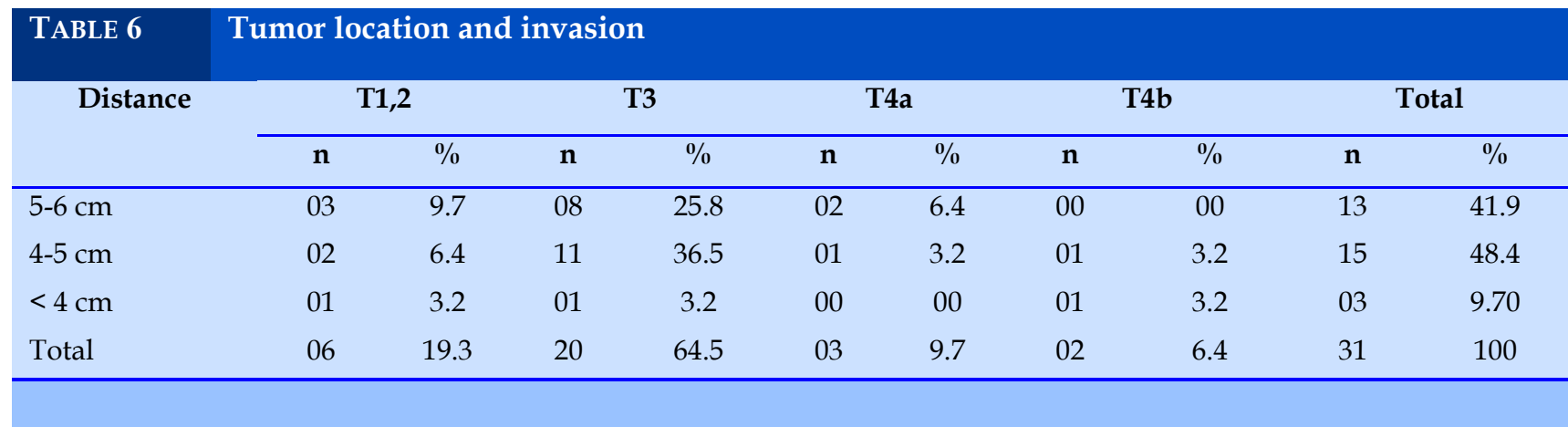

\section{Surgery methods}

\section{TABLE 7 Surgery methods}

\begin{tabular}{lcc} 
Surgery methods & $\mathbf{n}$ & $\%$ \\
\hline Cutting local tumor & 01 & 3.2 \\
Cutting low front tumor & 04 & 12.9 \\
Miles surgery & 03 & 9.7 \\
Schissel.R (ISR) Surgical & 21 & 67.7 \\
Artificial anus surgery & 02 & 6.4 \\
\hline
\end{tabular}

The methods of anti-stretching and pressure reduction

\begin{tabular}{lccc} 
TABLE 8 & $\begin{array}{l}\text { The methods of } \\
\text { pressure reduction } \\
\text { Methods }\end{array}$ & n & \% \\
\hline Sigma release & 25 & 100 \\
Spleen corner release & 06 & 24.0 \\
MTTD vessel knotting & 25 & 100 \\
Colon opening & 01 & 4.0 \\
Draining before the sacrum & 25 & 100 \\
Total & 25 & 100 \\
\hline
\end{tabular}

\section{Shaping the colon}

\begin{tabular}{lcc} 
TABLE 9 & Shaping the colon & \\
Methods & $\mathbf{n}$ & $\%$ \\
\hline No shaping & 06 & 28.6 \\
Shaping of "J" & 11 & 52.3 \\
Lateral shaping & 04 & 19.1 \\
Total & 21 & 100 \\
\hline
\end{tabular}

\section{Complications in surgery}

\section{TABLE 10 The complications in surgery}

\begin{tabular}{lll} 
Complications & $\mathbf{n}$ & $\%$ \\
\hline Rectal - vaginal wall surgery & 01 & 3.2 \\
Bleeding & 02 & 6.4 \\
Urinary tract damage & 01 & 3.2 \\
Bladder damage & 00 & 00 \\
Bruising in bowel straps & 01 & 3.1 \\
\hline
\end{tabular}

The complications after surgery

\begin{tabular}{lcc} 
TABLE 11 & The complications after surgery \\
Complications & n & $\%$ \\
\hline $\begin{array}{l}\text { Bowel semi-obstruction } \\
\text { surgery }\end{array}$ & 02 & 6.4 \\
$\begin{array}{l}\text { Wound infection } \\
\text { Redundant fluids }\end{array}$ & 03 & 9.7 \\
Connection wound leaking & 03 & 6.4 \\
\hline
\end{tabular}

The results of histopathology

\section{TABLE 12 The results of histopathology}

\begin{tabular}{lcc} 
Histopathology forms & $\mathbf{n}$ & $\%$ \\
\hline Adenocarcinoma- highly specific & 08 & 25.8 \\
Adenocarcinoma- moderately specific & 19 & 61.3 \\
Adenocarcinoma- slowly specific & 02 & 6.4 \\
Adenocarcinoma- not specific & 01 & 3.2 \\
Adenocarcinoma- mucous glands & 01 & 3.2 \\
\hline
\end{tabular}


The number of removed and metastatic lymph nodes

TABLE $13 \quad$ Lymph nodes

\begin{tabular}{lcccccc} 
Types of tumors & \multicolumn{2}{c}{ Group 1 } & & Group 2 & & Group 3 \\
\cline { 2 - 6 } Index & $\mathbf{n}$ & $\mathbf{0}$ & $\mathbf{n}$ & $\mathbf{0}$ & $\mathbf{n}$ & \% \\
\hline The number of lymph nodes removed & 185 & 48.4 & 160 & 41.9 & 37 & 9.7 \\
$\begin{array}{l}\text { The number of metastatic lymph nodes } \\
\text { The average number of lymph nodes }\end{array}$ & 42 & 48.3 & 34 & 39.1 & 11 & 12.6 \\
$\begin{array}{l}\text { The average number of metastatic lymph } \\
\text { nodes }\end{array}$ & & & $12.65 \pm 4.82$ & \\
\hline
\end{tabular}

\section{Sizes of the lymph nodes}

\begin{tabular}{|c|c|c|c|c|c|c|c|}
\hline \multicolumn{8}{|c|}{ TABLE $14 \quad$ Sizes of the lymph nodes } \\
\hline \multirow[b]{2}{*}{ Lymph node sizes } & \multirow[t]{2}{*}{ Metastatic types } & \multicolumn{2}{|c|}{ Metastatic lymph nodes } & \multicolumn{2}{|c|}{$\begin{array}{l}\text { Un-metastatic } \\
\text { lymph nodes }\end{array}$} & \multicolumn{2}{|c|}{ Total } \\
\hline & & $\mathbf{n}$ & $\%$ & $\mathbf{n}$ & $\%$ & $\mathbf{n}$ & $\%$ \\
\hline$<5 \mathrm{~mm}$ & & 34 & 12.9 & 229 & 87.1 & 263 & 68.8 \\
\hline $5-10 \mathrm{~mm}$ & & 37 & 37.7 & 61 & 62.3 & 98 & 25.7 \\
\hline$>10 \mathrm{~mm}$ & & 16 & 76.2 & 5 & 23.8 & 21 & 5.5 \\
\hline Total & & 87 & 22.8 & 295 & 77.2 & 382 & 100 \\
\hline
\end{tabular}

\section{Relapse rates}

\begin{tabular}{lll} 
TABLE 15 & Relapse rates & \\
\hline Relapse rates & $\mathbf{n}$ & $\%$ \\
\hline Local relapse & 01 & 3.2 \\
Local metastasis & 01 & 3.2 \\
Distant metastasis & 01 & 3.2 \\
Total & 03 & 9.7 \\
\hline
\end{tabular}

\section{Kirwan criteria}

\begin{tabular}{lcc} 
TABLE 16 & Kirwan criteria & \\
Kirwan criteria & $\mathbf{n}$ & $\%$ \\
\hline Kiwan I & 11 & 44 \\
Kiwan II & 08 & 32 \\
Kiwan III & 06 & 24 \\
Kiwan IV & 00 & 00 \\
Kiwan V & 00 & 00 \\
\hline
\end{tabular}

\section{DISCUSSION}

Age and gender

Low rectal cancer is more common in people over 60 years of age; men are more common than women. In our study, the group of over 60 years old accounted for $64.5 \%$, the average age of the group was $63.7 \pm$ 13.6, the male/female ratio was about 1.2. Truong Vinh Quy studied 52 cases in Hue Central Hospital with the rate of over 60 years old at $65.4 \%$ and male/ female at 1.17 [1].

\section{Clinical and subclinical}

In our study, the symptoms of bloody mucous stool accounted for $80.6 \%$, change of stool pattern accounted for $83.8 \%$, although this is not a specific symptom but it is very useful and a marker in colorectal cancer screening in general. Clinical symptoms that have a major impact on the colonoscopy decision because the endoscopy is still an invasive screening which needs to be prepared, often causes anxiety to the patient. Nguyen Hoang Minh studied 96 cases at $\mathrm{K}$ hospital with the rate of blood mucous stool at $80.2 \%$ and $87.5 \%$ of stool pattern change [2].

In the CEA cancer marker test, $41.9 \%$ of cases of CEA increase over $5 \mathrm{ng} / \mathrm{ml}$ showed that CEA sensitivity 
was not high and was often used for postoperative follow-up. In Tran Anh Cuong's study of 116 cases, the rate of CEA increase reached $46.6 \%$. Colonoscopy: images of lumpy tumors and ulcers account for 93.6\%. In addition, there is ring cell cancer, polyp's cancer. The hard infectious tumors were rare and difficult to diagnose. Truong Vinh Quy studied 52 cases, in which only 2 cases had hard infectious tumors. In the study of Schissel.R, the hard infectious tumor accounted about only $4-5 \%[1,3]$.

Imaging diagnosis: for rectal cancer, performing MSCT and MRI routinely has two purposes: to evaluate the levels of local invasion, sphincter invasion and distant metastasis. In case of distant metastasis, PET / CT are required. All cases in our study followed MSCT and MRI. There were $25.8 \%$ of cases with the invasion that crossed the rectum wall, of which $9.7 \%$ invaded nearby organs. The rate of sphincter invasion was about $42 \%$, of which internal sphincter invasion was $32.3 \%, 9.7 \%$ had the invasion in both sphincters. The rate of lymph nodes around the rectum and along the arteries was about $77.4 \% .2$ cases detected distant metastases (liver, lung) with one case of extensive invasive and one case of here and there metastasis. The study by Nguyen Hoang Minh showed that MRI has a sensitivity of $94.7 \%$, a specificity of $90.5 \%$ in assessing the level of invasion and lymph node metastasis [2].

Relating to the location and invasion level: the distance of the tumor to the anal edge is confirmed by endoscopy and MSCT / MRI image. 13 cases' tumors $(41.9 \%)$ were $5-6 \mathrm{~cm}$ from the edge of the anus. 15 cases' tumors $(48.4 \%)$ were $4-5 \mathrm{~cm}$ away and 3 cases under $4 \mathrm{~cm}$. In relation between tumor position and invasion, 4 cases of tumors above $4 \mathrm{~cm}$ have invasive levels of T4b. According Tran Anh Cuong, in high rectal tumors, the level of invasion, lymph node metastasis is 3.6 times higher than the low one [3].

\section{The surgery results}

Surgery method: depending on the location and the invasion level of tumors and body conditions, we chose different methods. There is one case of large polyps cancer without the invasion and lymph nodes around the rectum, we cut the mucous membrane and send for further treatment after surgery. There were 4 cases of low anterior cutting, 21 cases of cutting sphincter - ISR (Schissel.R surgery). There were still 3 cases of Miles surgery and 2 cases that we could only do artificial anus due to late stage and weak condition. Currently, studies show that rectal tumors rarely metastasize to less than $2 \mathrm{~cm}$, often have more horizontal metastasis; the degree of sphincter invasion will determine the method of surgery. Akasu $\mathrm{T}$ et al. in the study published in Japan in 2008 said that it was time to say no to artificial anuses, while Schissel.R led to cases of artificial mechanic anus $[4,5]$.

Regarding the anti-tension and pressure-reduction: the double-cutting of the mesenteric artery below the root, releasing the sigmoid colon in some cases was enough to bring the colon down at the anal canal. In some cases, Colon in the spleen angle must be released. There was one case with opening the ileum to the skin to reduce the pressure at the connection wound. This case was a 35-year-old patient who had chemo-therapy before surgery. After the surgery after 2 weeks of chemotherapy, we found that the colon straps colon has edema so we reduced active pressure, but then the patient still has the complication of vaginal rectal leakage. We carried out presacrum drainage to lateral shaping $100 \%$ along the trocar hole in the right pelvic area. The study of Ung Van Viet showed that the drainage of the ileus to the skin does not reduce the risk of leakage but has the effect of reducing the risk of re-surgery when being leaked [6].

About colon shaping: there were $23.8 \%$ of cases with no shaping, $47.6 \%$ of the cases "J" shaping, and 19.4 $\%$ with lateral shaping. Shaping colon or not based on many factors: the frequency of bowel movement before the surgery, sphincter function, the length of the colon after cutting, colon mesenteric thickness, the diameter of the colon, pelvic diameter, etc. In this study, in cases under 60 years of age, with bowel movement frequency less than 2 times a day, we did not perform colon shaping but connected the colon directly to the anal canal. Colon shaping was divided into 2 groups, shaped "J" and lateral shaping, depending on the length of the colon after cutting, mesenteric thickness and pelvic diameter. When having the rectum cancer, patients more or less have colon flow stagnant. In these cases, we found that the diameter of the colon stretched over $5 \mathrm{~cm}$, so the colon diameter has little impact on the shaping method in our study. Schissel R tended to do the colon shaping, basing on the length of the colon after cutting compared to the anal edge. With the length of over $5 \mathrm{~cm}$, a "J" shaping was made while that of less than $5 \mathrm{~cm}$, vertical cutting and horizontal stitch was done [4].

About complications in surgery: the complication occurred with the group of surgery to preserve sphincter and Miles surgery, with the damages of the ureters, bladders, vaginal rectal sides or bruising intestinal straps. In our study, there were 2 cases of bleeding, 1 case of ureter damage, 1 case of bladder damage, and 1 case of bruising intestinal straps which must be done to release the colon of the spleen angle to make it lower. In the study by Mai Dinh Dieu, the complication rate was about 3\%; our complication rate was higher because our sample size was not large enough. In the study of Portier G 
and Cs, the rate of complication in surgery ranged from $3.6-5 \%[7,8]$.

Regarding the complications after surgery: the common complications included intestinal obstruction (2 cases), wound infection ( 3 cases) and fluid residues ( 2 cases) and junction leakage complications (3 cases). The complication of junction mouth leakage was worrying, causing patients to face the risk of having surgery to make an artificial anal. This complication often occurs in cases where there was no good draining of residual fluid. We manage by rotating the drainage tube, puncturing to suck the fluid out through ultrasound, increasing antibiotics and continuously draining before the sacral bone.

About histopathology: the results of histopathology

\section{CONFLIT OF INTEREST}

Non.

\section{REFERENCES}

1. Truong Vinh Quy. Evaluating the results of treatment of low rectal cancer treatment by sphincter conservation endoscopic surgery. Doctoral thesis, Hue Medical University; 2018.

2. Nguyen Hoang Minh. Lymph node metastasis in rectal cancer against histopathology and MRI. Doctoral thesis, Hanoi Medical University 2017.

3. Tran Anh Cuong. Characteristics of lymph node metastasis and results of rectal cancer surgery at $\mathrm{K}$ hospital. Doctoral thesis, Hanoi Medical University 2017.

4. Schiessel R, Novi G, Holzer B. Technique and LongTerm results of intersphincteric resection for low rectal cancer. Dis Colon Rectum 2005;48: 1858-1867.

5. Akasu T, Takawa M, Yamamoto S. Intersphincteric resection for very low rectal adenocarcinoma: Univariate and Multivariate analyses of risk factors for recurrence. Annals of surgical oncology 2008;15(10): 2668-2676. after surgery are mostly adenocarcinoma, with different specifications. The majority is moderate specifications with $61.3 \%$. Those cases had over 12 nodes removed. The average number of lymph nodes removed was $12.65 \pm 4.82$, the number of metastatic lymph nodes was $5.63 \pm 2.7$. The higher the tumors were, the higher the rate of invasion and lymph node metastasis were. The size of the lymph nodes over $10 \mathrm{~mm}$ was about $76.2 \%$. In the study of Tran Anh Cuong, the metastasis rate of lymph nodes over $10 \mathrm{~mm}$ was $84.4 \%$ [3].

About follow-up examination: although the followup time was not long, we have recorded 1 case of local relapse and 2 cases of metastatic invasion. In terms of the ability to sphincter self-control, all cases had Kirwan scores below 3 and got better.

6. Ung Van Viet. The role of open anatomy in low-end laparoscopic surgery in the treatment of low rectal cancer. Doctoral thesis, Ho Chi Minh City University of Medicine and Pharmacy - 2017.

7. Mai Dinh Dieu. Research and application of endoscopic surgery to treat rectal cancer. Doctoral thesis, Hue University of Medicine - 2015.

8. Portier G, Ghouti L, Kirzin S. Oncological outcome of ultra-low coloanal anastomosis with and without intersphicteric resection for low rectal adeocarcinoma. British journal of surgery 2017;94: 341-435.

9. Rullier E, Cunha A. SA, Couderc P. Laparoscopic intersphincteric resection with coloplasty and conoanal anastomosis for mid and low rectal cancer. British journal of surgery 2013;90: 445-451.

10. Yamada K, Ogata S, Saiki Y. Functional results of intersphincteric resection for low rectal cancer. British journal of surgery 2007; 94: 1272-1277. 